\title{
AN ANALYSIS OF THE INFLUENCE OF ANNUAL RAINFALL FLUCTUATIONS ON WILDFIRE OCCURRENCE IN PROTECTED AREAS IN THE NORTHWEST OF ZIMBABWE
}

\author{
Mukululi Ndlovu ${ }^{1}$ and Innocent Mahakata ${ }^{2}$ \\ ${ }^{1}$ Zimbabwe Parks and Wildlife Management Authority, P Bag 5926 Victoria Falls, \\ Zimbabwe. \\ Email: anjovum@gmail.com
}

\begin{abstract}
${ }^{2}$ Zimbabwe Parks and Wildlife Management Authority, Sengwa Wildlife Research Institute, Bag 6002, Gokwe.

Email: innocentmahakata@gmail.com
\end{abstract}

Cite this article:

Mukululi N., Innocent M. (2021), An Analysis of the Influence of Annual Rainfall Fluctuations on Wildfire Occurrence in Protected Areas in the Northwest of Zimbabwe. African Journal of Environment and Natural Science Research 4(3), 93107. DOI: 10.52589/AJENSRDEYOLNL5.

\section{Manuscript History}

Received: 17 June 2021

Accepted: 14 July 2021

Published: 9 Aug 2021

Copyright $\odot 2020$ The Author(s). This is an Open Access article distributed under the terms of Creative Commons AttributionNonCommercial-NoDerivatives 4.0 International (CC BY-NC-ND 4.0), which permits anyone to share, use, reproduce and redistribute in any medium, provided the original author and source are credited.
ABSTRACT: The occurrence and threat from wildfires are a conservation concern in semi-arid savanna-protected areas. The risk of wildlife occurrence is uncertain under climate change scenarios. However, general predictions are that different changes are likely to occur in weather conditions in different landscapes. We sought to analyze the influence of annual precipitation on wildfire occurrence in a protected area landscape in northwest Zimbabwe. Data on annual rainfall received and wildfire occurrence for Chizarira National Park (CNP), Chirisa Safari Area (CSA), and Sengwa Wildlife Research Area (SWRA) was analyzed using regression analysis. The relationship between the annual precipitation amount received per site and the number of wildfires recorded per site showed a positive correlation only for CSA. No significant differences were observed for CNP and SWRA at a significant level of $p<0.05$. The highest number of wildfires were recorded between July and November. We advance that annual rainfall is one factor among many drivers of wildfires and that this is not uniform but varies across the landscape. Effective annual precipitation contributes to high vegetation biomass production and accumulation of such biomass increases the risk of wildfires. In some instances, rainfall patterns could not explain the occurrence of wildfires. We, therefore, contend that other drivers such as human activities and natural factors are important drivers of wildfires across the three sites. The conservation implication of our finding is that robust fire management plans need to take an ecosystem approach that includes communities adjacent to protected areas.

KEYWORDS: Effective Rainfall, Wildfires, Chizarira National Park, Chirisa Safari Area, Sengwa Research Area. 


\section{INTRODUCTION}

\section{Background}

Fire affects virtually all terrestrial ecosystems but occurs more commonly in some landscapes than in others (Csiszar et al., 2005; Lafon \& Quiring, 2012). Fire activity is related to both climate variables and human factors but displays a stronger relationship with precipitation variability (Wilgen \& Govender, 2004). Protected areas in northwest Zimbabwe are particularly noteworthy for their high wildfire activity, which is associated with hot dry seasons, and a variable precipitation regime, which promotes heavy fuel production and rapid drying of fuels.

Fire is an influential disturbance agent and a major natural hazard that presents complex management challenges (Lafon \& Quiring, 2012). Vegetation and high accumulation of moribund materials as a result of good annual precipitation affect fire occurrence (Alaback et al., 2003). Annual precipitation is of fundamental importance in defining the conditions that permit fire and studies have shown how annual precipitation helps shape landscape patterns of fire (Krawchuk et al., 2009). The propensity of savanna to burn increases with rainfall with areas receiving $>700 \mathrm{~mm}$ having high chances of fire occurrence (Wilgen, 2006). Elsewhere, fire studies in Kruger National Park indicate an increase in the extent of the area burnt with increased rainfall (Smit et al., 2013).

The annual precipitation varies annually while landscape variation also exists in the amount of rainfall received (Balfour and Howison, 2015). A fuller understanding of how annual rainfall variation shapes fire occurrence requires consideration of analysis over a large landscape. Although arid environments occasionally experience fires, studies have demonstrated that episodic unusual dry periods exacerbate fire incidences (Westerling et al., 2006). A better understanding is therefore needed of how annual rainfall fluctuations and variability influence the overall susceptibility of an environment to fire.

Wildfire is a large-scale complex system in Sebungwe Region and other parts of protected areas world-over and on the ecological front, the major disturbances that are likely to generate homogeneity in the system (Cumming, 2008). Insight into the mechanism that drives wildfires in Chizarira National Park (CNP), Chirisa Safari Area (CSA), and Sengwa Research Area (SWRA) can be revealed by the distribution of the wildfire over a large time scale, which is one of the important topics in wildfire research in Zimbabwe. Wildfires in Zimbabwe are seriously threatening the stability and balance of the ecosystem in the Kavango-Zambezi Transfrontier Area (Mpakairi et al., 2018). They are one of the most serious natural disasters because they restrict the protection of protected area biodiversity (Nelson \& Chomitz, 2011).

Every year prescribed burning is done in CSA, CNP, and SWRA. However, the size of areas burned by wildfires was observed to vary annually. Fire frequency has been attributed to annual rainfall in northwest Zimbabwe and the fire return interval varies across the landscape. There has been an assumption that in CNP, CSA, and SWRA fire caused by climate factors such as annual precipitation meant that wildfire is randomly distributed and that it is impossible to forecast wildfire risk reliably within the CNP and CSA landscape.

Wildfires are driven by dry conditions, high dry biomass, high or variable winds, and human population density (Mpakairi et al., 2018). While many fire incidences remain unaccounted for, the main source of fire is related to anthropogenic factors (Bowman et al., 2011). Hence, 
(Nyamadzawo et al., 2013) observed wildfire occurrences are affected by multiple coupled, complex systems, such as anthropogenic activities like clearing lands for agriculture and natural factors such as lightning. This research focuses on the effect of annual precipitation amount received on wildfire occurrence in CNP, CSA, and SWRA which has been facing the threat of fires in the last decades. Spatial differences in fire occurrence across protected areas and adjacent communities in the northwest of Zimbabwe concerning annual precipitation variability are still unknown.

Fire studies in CNP and CSA did not put much emphasis on the amount of annual rainfall received as a key determinant factor of fire occurrence in the preceding year. Understanding the relationship between annual precipitation fluctuations and wildfire occurrence in the northwest, Zimbabwe is fundamental in assessing the vulnerability of the landscape to wildfires. Fire has become a high-risk threatening biodiversity loss through ecosystem change. With climate change upon us this risk is predicted to increase. Fire management in Southern Africa has been achieved through adaptive management with certain lessons learned in different protected area fire experiments and monitoring work. This is still an ongoing and reliable approach despite its limitations.

We sought to determine how annual rainfall and variations in interannual rainfall influence, and determine variations in wildfires occurrence in CNP, CSA, and SWRA. We used readily available open-source data from the National Aeronautics and Space Administration (NASA) Fire Information Resource Monitoring System (FIRMS) spanning 20 years from 2001 to 2020 and annual rainfall data to establish the relationship between annual rainfall and wildfire occurrence. We sought to validate the hypothesis that annual rainfall fluctuations influence fire occurrence in the corresponding year and that wildfire occurrence varies across the landscape along a precipitation gradient.

\section{MATERIALS AND METHODS}

\section{Study area}

The CNP, CSA, and SWRA are part of the Sebungwe landscape. CNP lies in northern Zimbabwe and is $2000 \mathrm{~km}^{2}$ in extent, it is the third-largest national park in Zimbabwe. CSA is $1713 \mathrm{~km}^{2}$ while SWRA is just $373 \mathrm{~km}^{2}$ and the smallest of the three areas. The landscape is characterized by three seasons consisting of a dry hot season from August to November, a hot rainy season from December to April, and a cold dry season from May to July. The selected areas are heterogeneous in terms of vegetation, topography, and climate, and have experienced extensive wildfires historically and in recent decades, some of which have burned severely. The landscape is managed as a protected area surrounded by communal areas. 


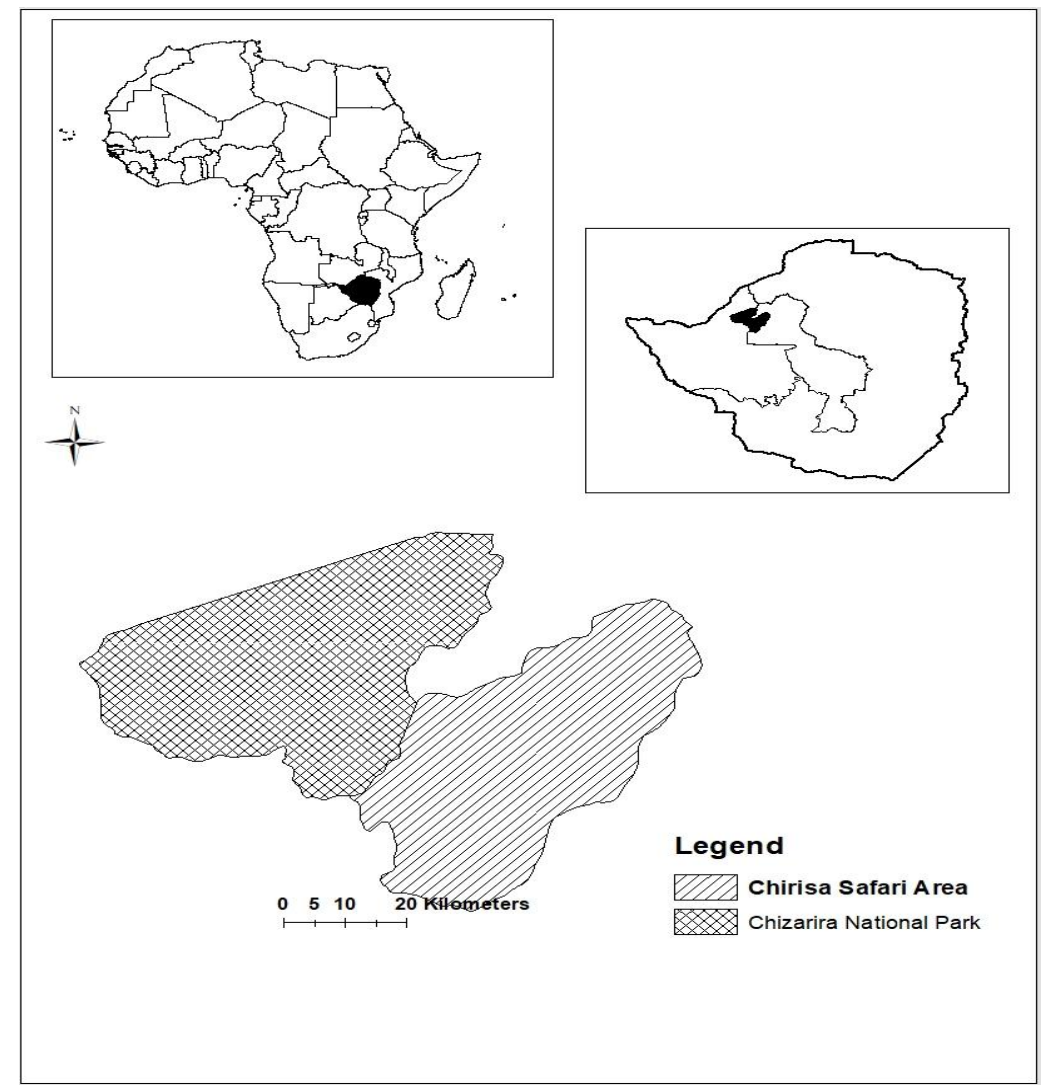

Figure 1: Map showing the location of study sites north-west Zimbabwe, Sebungwe Region. Sebungwe region is made up of Chizarira National Park and Chirisa Safari Area. SWRI is part of the Chirisa Safari Area.

\section{Vegetation}

Vegetation types across the landscape range from those found in relatively moist conditions along the riverine in the central and northern east of the landscape to much drier ones found in high terrains. Soil moisture availability, resulting from an interaction of rainfall, topography, soil texture, soil depth, drainage, and rooting habits, is shown to be a major factor in determining the distribution of vegetation types across the landscape. Most dominant vegetation types include Miombo woodlands, Mopane, Combretum, and mixed vegetation in higher grounds while grasslands are a characteristic of most wetland and riverine vegetation.

\section{Data Collection}

In this study, annual precipitation and fire occurrence data were used. Data on rainfall from 2001 to 2020 for three sites (CNP, CSA, and SWRI) was obtained from national park records. The Moderate Resolution Imaging Spectroradiometer (MODIS) fire point data from the NASA Fire Information for Resource Management System (FIRMS) at https://firms.modaps.eosdis.nasa.gov/ download/. Further fire incidence records were obtained from the station records. The MODIS fire data has been used extensively in wildfire studies the world over (Mwangudza et al., 2013; Mpakairi et al., 2018). The active fire data represent fire activity in 1-km pixel within the satellite's swath during the time of the satellite overpass. 
We used data from January to December for the period 2001 to 2020. We adopted the two fire season categories-pre fire season and fire season (EMA Act Chapter 20:27) with an extension beyond the national fire season ( 31 October) to account for fires that occur before the onset of the rain season. All management fires were not included for this study. The pre fire season is a period when pre fire suppression measures such as fire guards, early block and random burning is done. The fire season is characterised by the hot dry season when unplanned fires mostly occur. The seasonal classification allowed for comparison between management and wildfires.

\section{Data Analysis}

The long-range correlations between the wildfire occurrence and annual precipitation were analyzed using MINITAB-17 statistical software. A time series of cumulative annual precipitation (mm per annual rain season) derived from three sites (CNP, CSA, and SWRI) and wildfire occurrence data was performed. Kruskal-Wallis analysis (Zar, 1999) was used to test whether the rainfall fluctuation and number of wildfires differed among the three areas selected. We performed pairwise comparisons between sites in PAST Version 2.16 statistical software.

\section{RESULTS}

\section{Rainfall Trends}

Annual rainfall fluctuation varies on a year-to-year basis as well across the three sites. CNP dominantly received higher rainfall in most years compared to the other two sites. However, for CSA, some data was missing on rainfall. Annual rainfall trends for the three sites are indicated in (Figure 2) below. The most fire incidents were recorded in CNP followed by CSA and SWRI had the least among the three protected areas. High wildfire occurrences were recorded between July and October.

Kruskal Wallis test for pairwise rainfall variation among the three sites showed a significant difference in annual rainfall received. CNP receives high rainfall compared to CSA and SWRA with a significant difference of 0.01653 and 0.003639 respectively. However, for CSA and SWRA, there was no significant difference $(0.4311)$ at $p<0.05$. 


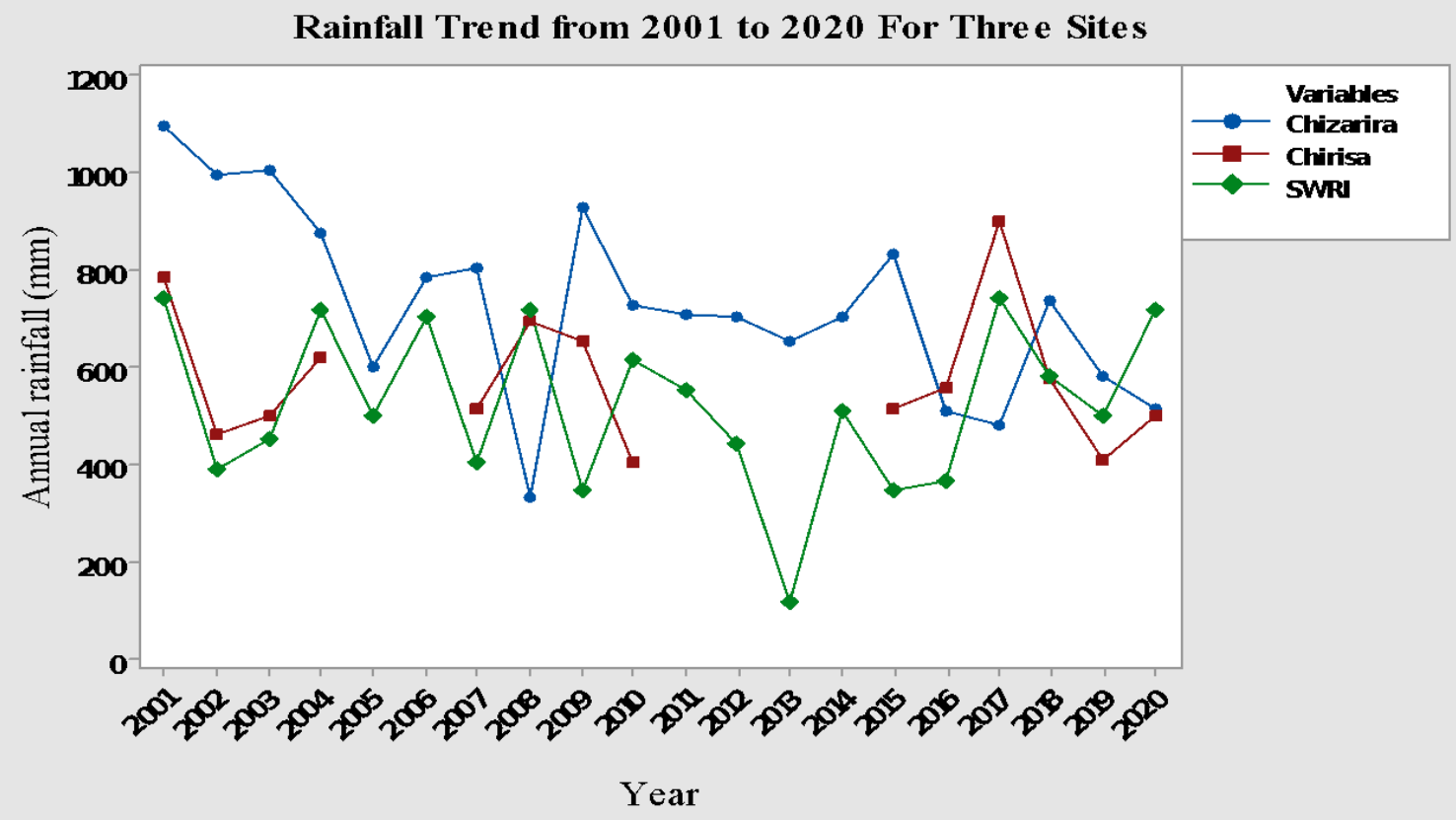

Figure 2: Annual rainfall trends in CNP, CSA, and SWRI and variation across the landscape based on the amount of rainfall recorded at each site.

\section{Wildlife Occurrence and Trend}

Wildfire trends for the three sites from 2001 to 2020 showed variation among sites and from year to year. Generally, CNP recorded the highest number of wildfires for the period. On the other hand, SWRA recorded the lowest number as well as the size of the area burnt each year.

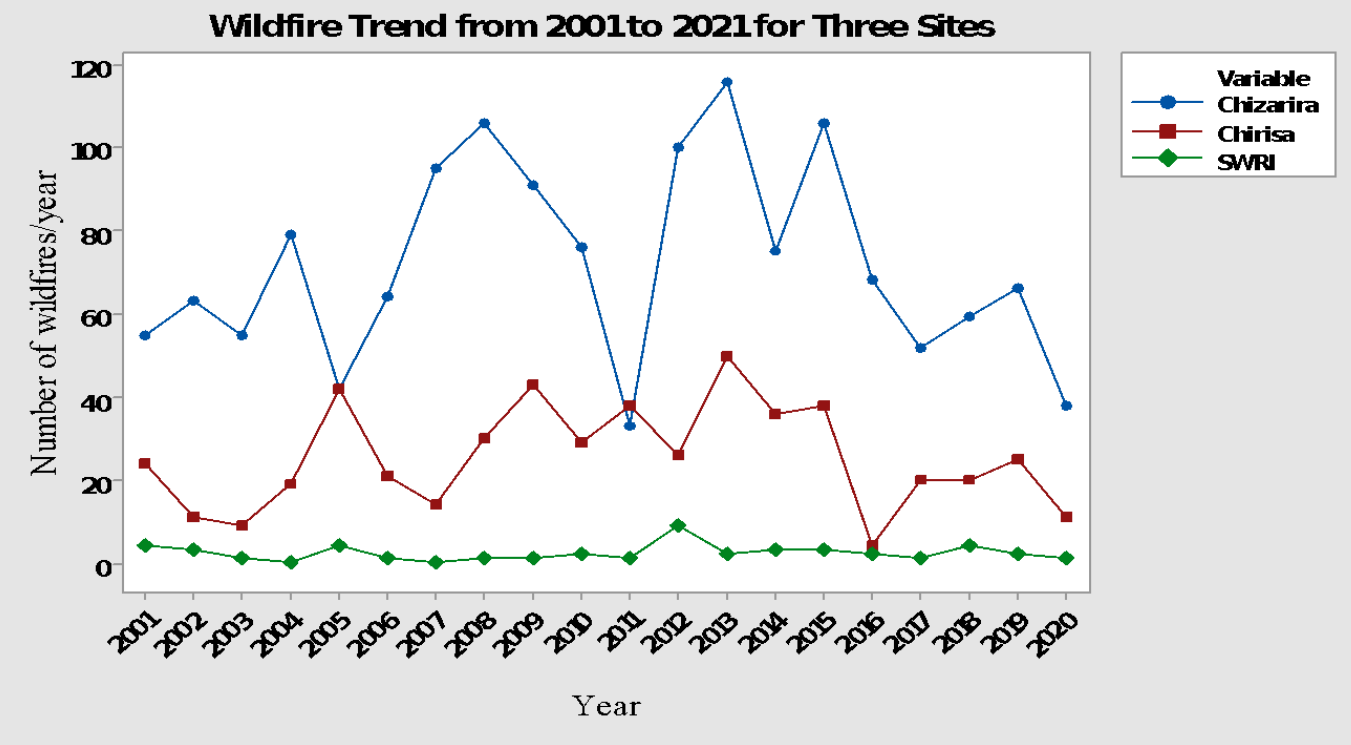

Figure 3: Graph showing changes in wildfires recorded from three sites from 2001 to 2020 . CNP recorded the highest number of wildfires from 2001 to 2020 , whilst the lowest was recorded in SWRI. 
African Journal of Environment and Natural Science Research

ISSN: 2689-9434

Volume 4, Issue 3, 2021 (pp. 93-107)

Specific area wildfire, percentage area burnt, and annual rainfall trends

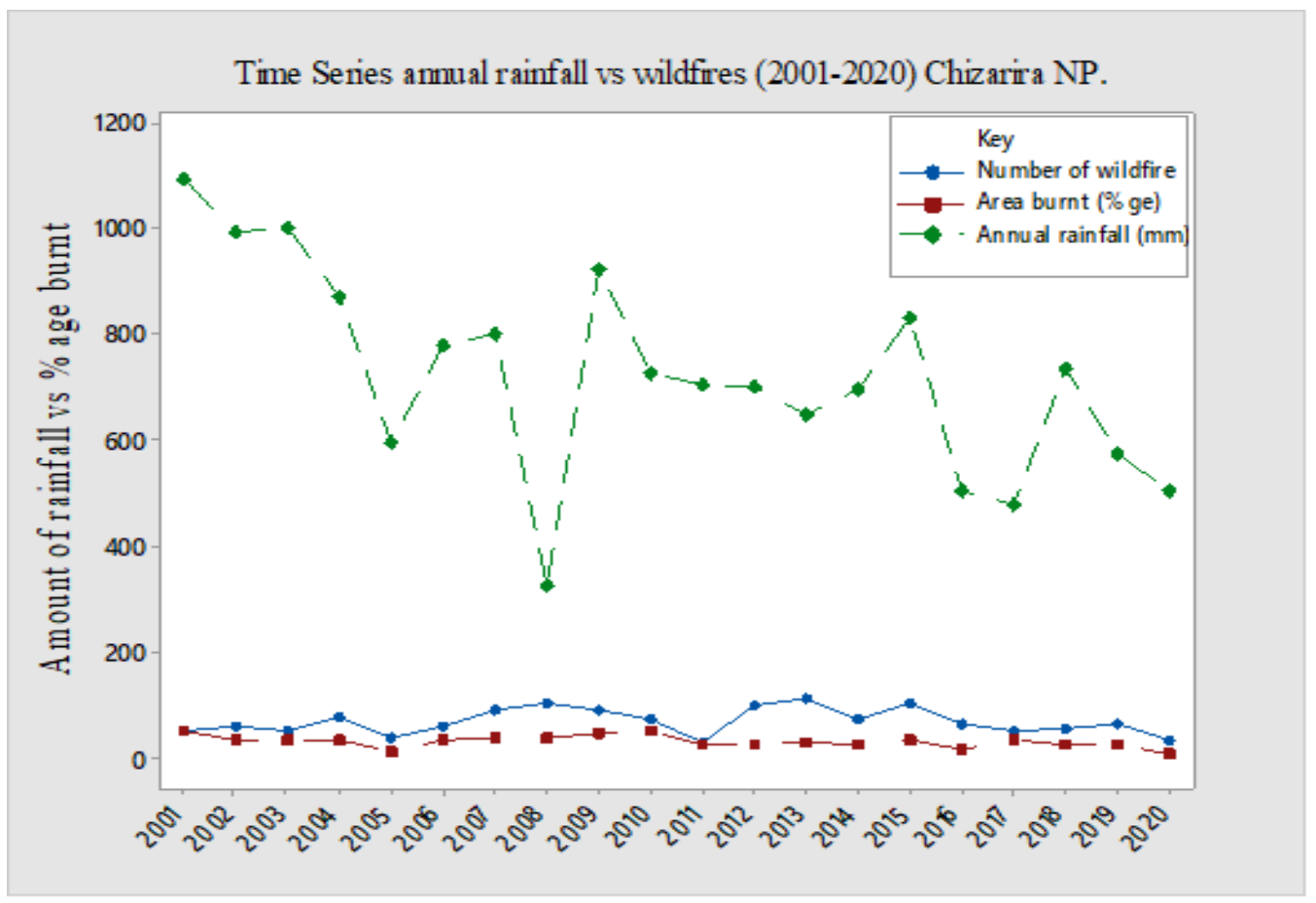

Figure 4: Chizarira National Park wildfire, percentage area burnt, and annual rainfall status trends

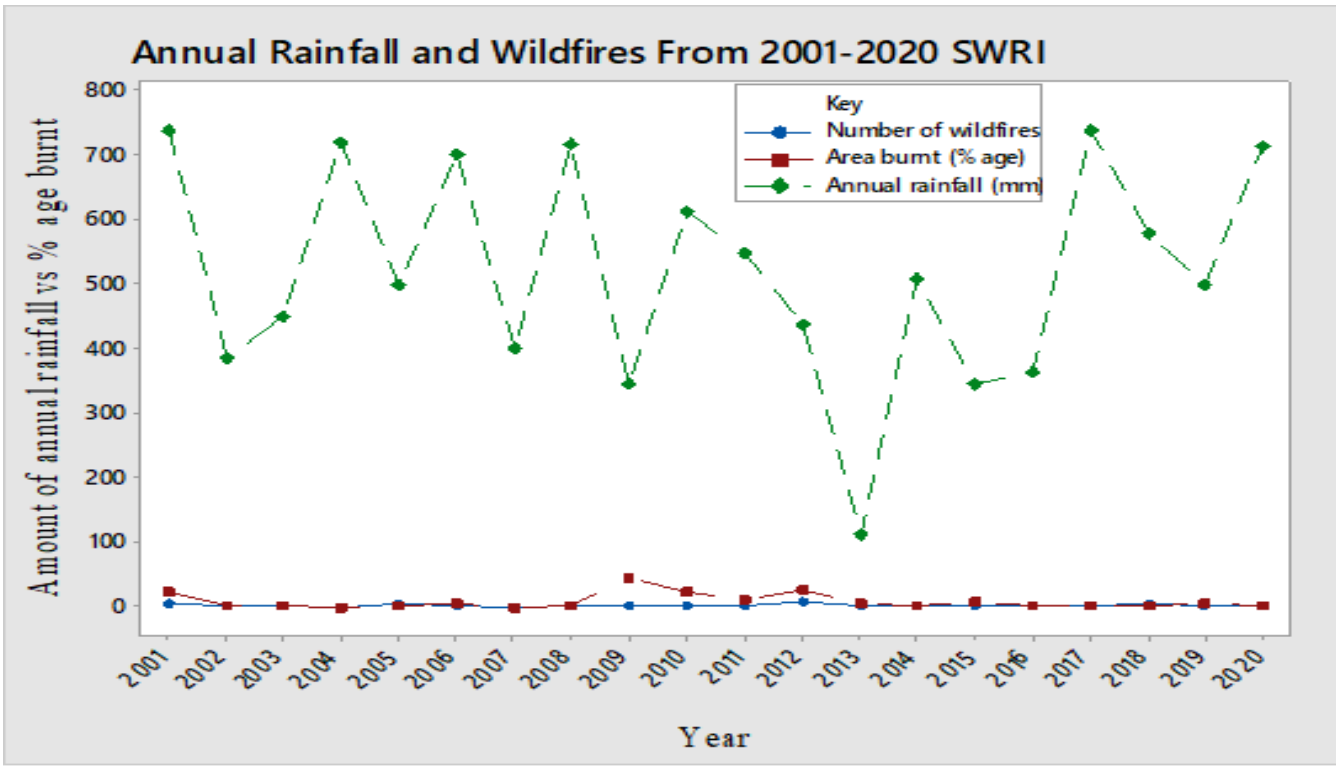

Figure 5: SWRI wildfire, percentage area burnt, and annual rainfall status trends. 
African Journal of Environment and Natural Science Research

ISSN: 2689-9434

Volume 4, Issue 3, 2021 (pp. 93-107)

www.abjournals.org

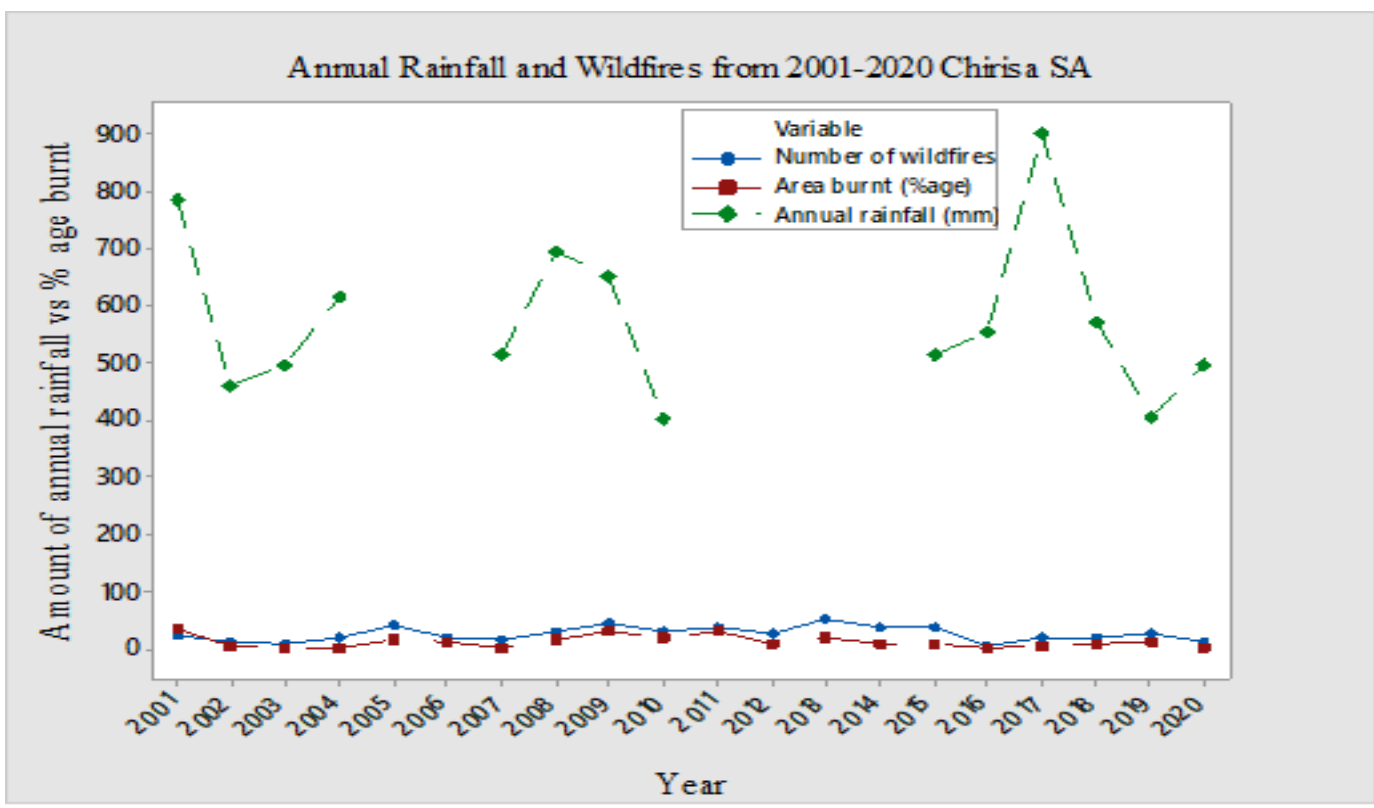

Figure 6: Chirisa Safari Area wildfire, percentage area burnt, and annual rainfall status trends. There was some gap in rainfall data for the study area. The highest rainfall was recorded in 2017.

\section{Correlation between rainfall and wildfires}

The relationship between annual rainfall and the corresponding season wildfire occurrence was performed for CNP, CSA, and SWRI.
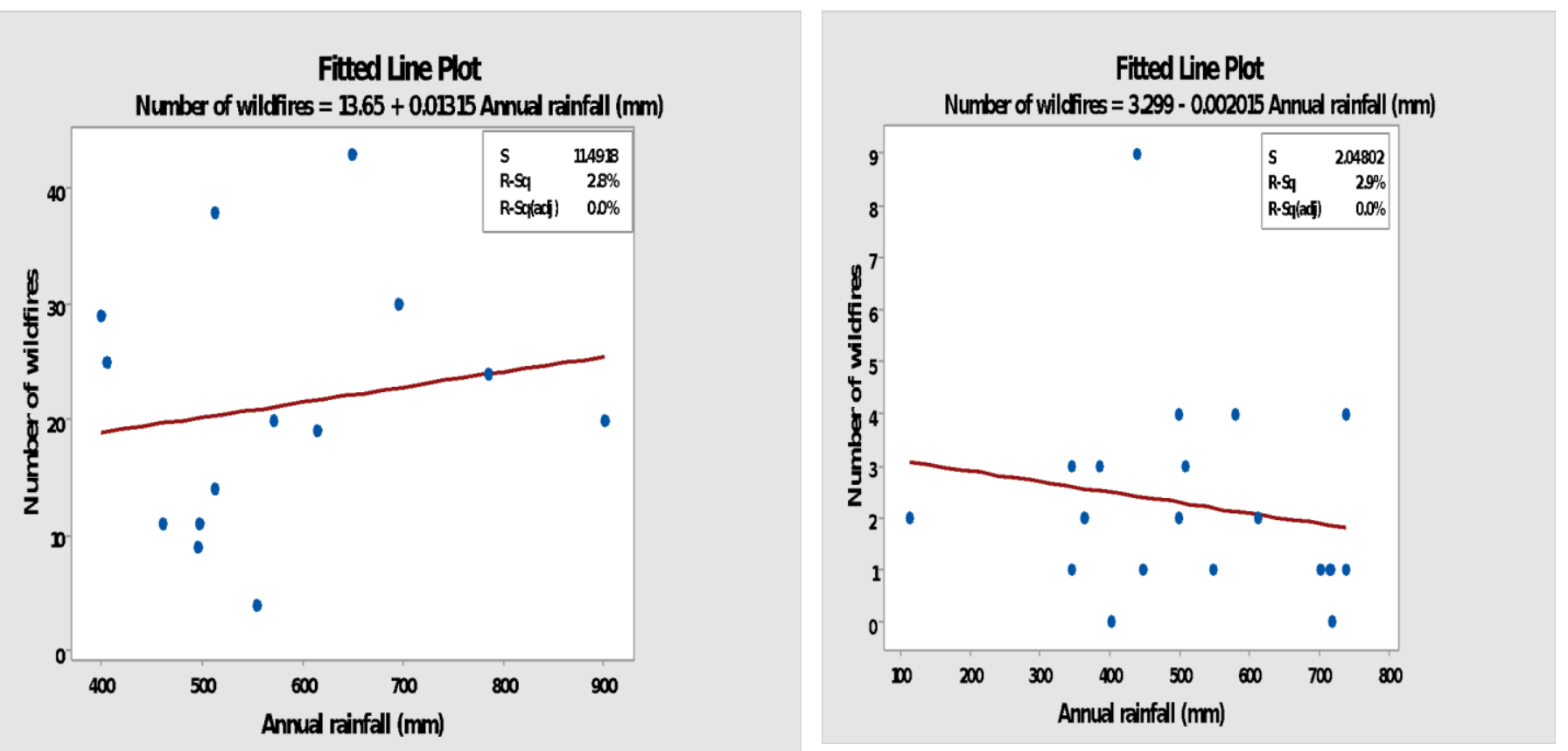


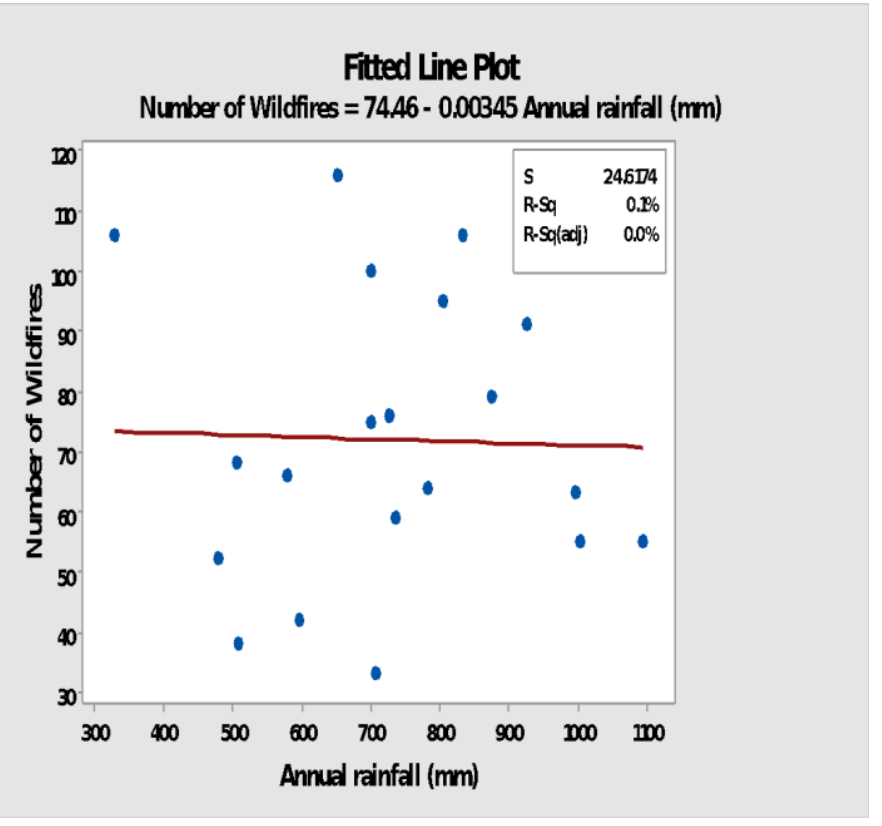

Figure 7: The relationship between the annual precipitation amount received per site and the number of wildfires recorded per site. Person's correlation showed significant evidence for CSA and CNP and SWRA no significant evidence ( $p<$ 0.05 ) for the association between annual precipitation and number of wildfires.

\section{A variation on wildfire occurrence for each month}

Box plot to test the significant difference in wildfires occurrence across three sites was done for each month comparing the three sites.

\section{Boxplot of J anuary, February, March, April, May, J une, J uly, ...}
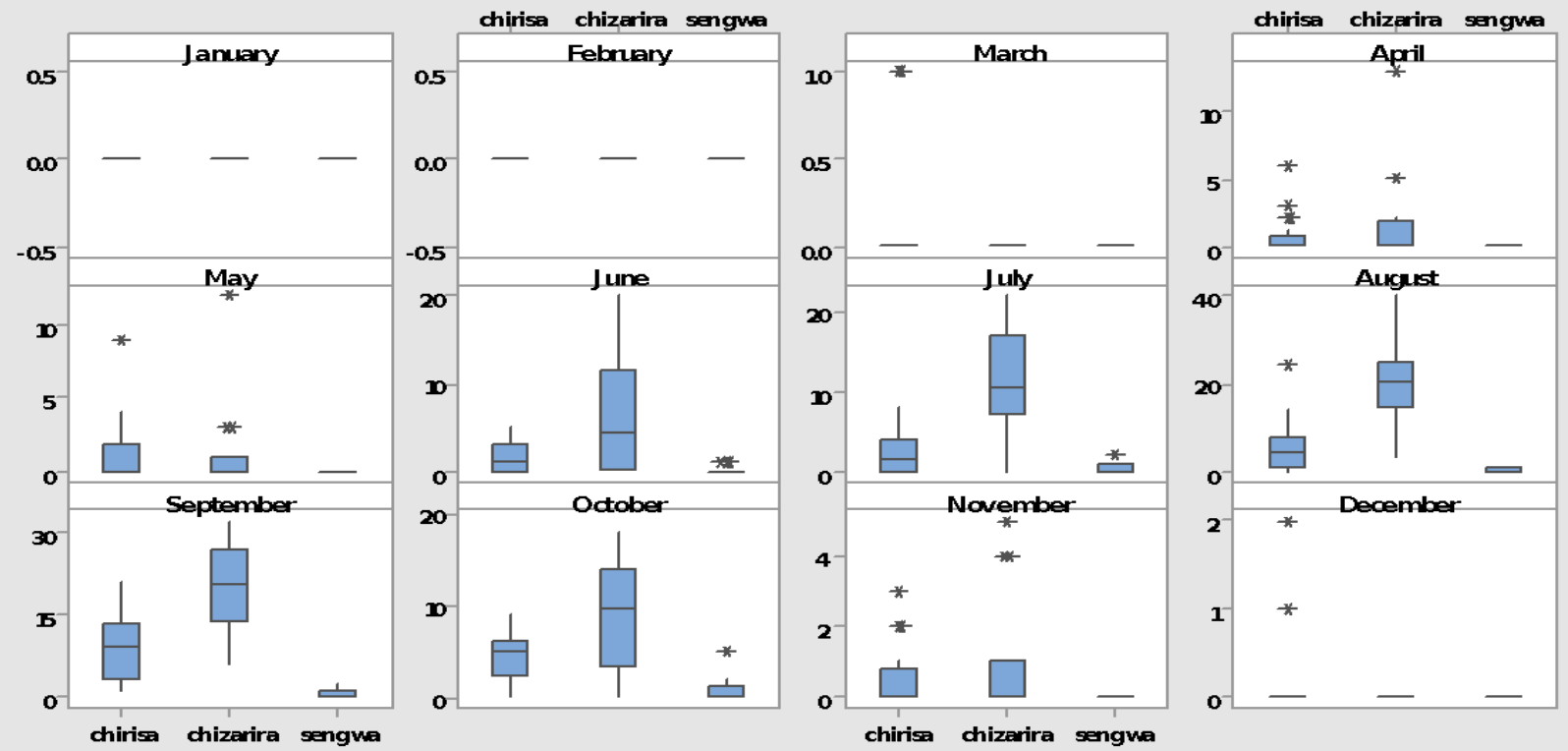

station

Figure 8: Graph showing comparison on significant difference per month of wildfire over years (2001 to 2020). 
The difference in the number of wildfires recorded over 20 years per month from three sites plotted using Box and Whisker where $p<0.05$. High wildfire occurrence was recorded between July and October and results showed a significant difference at $p<0.05$ while December to June showed no significant difference in wildfire occurrence across the landscape.

\section{DISCUSSION}

A better understanding of the role played by annual rainfall to wildfire occurrence assists Park managers in making informed choices on where wildfire occurrence is expected to be high and risks associated with such occurrence. We noted that across the three sites, annual rainfall received indicated less role in influencing areas burnt by wildfires in the corresponding season. Even though CSA showed a positive relationship between amounts of rainfall received to the number of wildfires recorded, the relationship was not significant to conclude annual rainfall plays a role in wildfire occurrence.

The conclusion was supportive of the results obtained from CNP and SWRA where there was a negative relationship suggesting annual wildfires cannot be ascertained as the main factor contributing to wildfire occurrence across the sites. Critical also is the aspect of effective rainfall which determines productivity (Dudley et al., 2001). Other factors such as anthropogenic activities outside and illegal activity within protected areas may be arguably contributing to a large extent to wildlife occurrence (Chingono and Mbohwa, 2015; Falk et al., 2011; Renard et al., 2012; Mpakairi et al., 2018).

Although this study reported a decrease in wildfire occurrence in CNP and CSA from 2015 to 2020 , other studies found no evidence of increasing or decreasing trends over time suggesting that trends could be quite variable among the three sites (Mpakairi et al, 2018). On the contrary, CNP and CSA showed an increase in wildfire occurrence, from the 2001 to 2015 period. However, our study observed wildfire occurrences varied spatially across the three sites. This could be a function of the varying environmental variables that exist across the study area and not a direct response to annual rainfall received at each site.

The number of wildfires and the total burned area was recorded high in CNP and CSA, a clear trend of the increasing occurrence of wildfires over the past years, however, it was not always the rule, as there is wide geographic variability as well less number of wildfire occurrence from 2016 to 2020. Overall, it appears the number of wildfires recorded at each site cannot be closely linked to the amount of annual rainfall received from the previous year.

Contrary to what could be expected from the fuel-age paradigm which states that fuel reduction as a consequence of wildfires would reduce the risk of future fires (Zedlerand Seiger, 2000), there is evidence that areas previously burned were characterized by repeated burn when compared to areas that were never burned in CNP and CSA. It would be expected that areas that are not frequently burnt will be high-risk areas for wildfires. Repeated burning in certain areas cannot be linked to annual rainfall received alone but other environmental issues such as vegetation type, topography as well human influence which involves planned and unplanned burning.

In CNP and CSA the number of fires recorded each year corresponds well with the size of the area burnt, however, this was not the case with SWRA. Fire incidence varies from year to year 
regardless of the amount of rainfall received. Data collected from the CSA indicated a positive relationship between annual rainfall and the corresponding fire incidence suggesting annual precipitation influence. However, in SWRI and CNP the results showed a difference which indicated a negative relationship though not significant enough to conclude rainfall influence on wildfire.

Mean annual precipitation from three sites varied spatially according to the generally recognized pattern across the southern savannah landscape which has been observed elsewhere (Wilgen, 2006). CNP recorded a higher annual precipitation amount than CSA and SWRA over the period 2001 to 2020. In terms of landscape characteristics, the three sites are more or less similar. However, some wildfire occurrences appear to be linked to the spatial patterns in annual precipitation as high fire incidences and area burnt were also high in CNP which received comparatively higher rainfall. Precipitation variability appears therefore partly explains the spatial differences in fire occurrence across a large landscape.

Across the three areas, wildfires were recorded high from August to October which corresponds to the national fire season. Dry season fires are driven by high temperatures and low humidity, elevation, Normalized Difference Vegetation Index (NDVI) a proxy for vegetation structure and human population density resulting in the high number of wildfire incidences and size of areas burnt (Mpakairi et al., 2018).

In both good and bad rain years, the incidence of wildfires during the period was almost equally similar. The number of wildfire occurrences between December and April each year was very low as expected corresponding to the rainfall season. However, wildfire incidence increased variably from August to November across the three sites.

Besides annual rainfall received, other factors such as differences in terrain aspect, vegetation, and human accessibility may account for fire activity in protected areas. CNP is a Miombo woodland characterized by tall Hyparrhenia grass species which are known to produce high fuel load. On the other hand, CSA and SWRA are dominated by Mopane woodlands with fewer grass species found except along the flood plains of major rivers such as Europe and Sengwa as well in Matsakinya vlei.

The peripheries of CSA and CNP in the southwest boundary reported the highest fire incidence from 2001 to 2020 than any other area probably because it shares boundaries with highly populated communal areas (Mpakairi et al., 2018). This is supported by earlier observations that increased settlement of people around protected areas in Sebungwe Region after tsetse eradication in the late 1970s increased the occurrence of wildfires in the area (Mapaure and Campbell, 2002). Although it is difficult to ascertain the actual cause of fire outbreaks, there is no doubt that human activity could be the main source (Bistinas et al., 2014). Hence, the interaction of anthropogenic factors, together with weather-related factors, may lead to an increase in the number of wildfires in the three sites.

Slope position and aspect also contribute to conditions that influence wildfire occurrence. Wildfire distribution across the three sites in both mid-and upper-slope positions experienced higher fire occurrence across three sites compared to lower-slope positions. One likely cause is that wind speeds are often greater in upper-slope positions (Bradstock et al., 2010). Topography could have affected fire occurrence and area burnt in CNP mostly. Topography 
structure influences wind direction, microclimates aspects such as wind and moisture content that determine vegetation structure and species composition.

While in the SWRA it appears that topography plays a less important role in determining what is burned by fires, in the CNP selectivity by fire towards certain landscapes and vegetation types may suggest the role of topography as critical to determining the size of area burnt by wildfires. Topography also influences roads, human settlements, and urban interfaces which increase the sources and risk of fire ignition (de Vasconcelos et al., 2001). Large fires are more common in the periphery of CNP and CSA suggesting a human influence on wildfire occurrence across the three sites. In CNP probability of wildfire occurrence has been estimated at higher altitudes because of a higher likelihood of human use of fire for poaching. Management anti-causative strategies such as anti-poaching bases reduce incidences of fire (Srivastava et al., 2014).

Wildfires can raze down extensive landscapes posing a major threat to the survival of terrestrial species and natural processes such as nutrient cycling where there are no robust fire management measures. As such, wildfire management, which often entails controlled burning and the development of fireguards, becomes critical to suppress and reduce the size of the area burnt. The occurrence of wildfires has fallen from 2001 to 2020 across the sites. Both the number of fires and the percentage of areas burned by wildfires indicated a continued decline. This can be attributed to the introduction of a program of early burning of peripheral areas of all sites to reduce incidences of wildfires originating from the communal lands.

Fewer wildfires have been reported in SWRA since 2001, probably because of well-developed fireguards and the size of the area which is small compared to CNP and CSA. A program of early burning of peripheral areas of SWRA, which was initiated in 1979, led to significant reductions in wildfire occurrence (Mapaure et al., 2009). CNP and CSA reported large areas burnt by wildfires and this was related to space firebreaks compared to SWRA. However, CNP and CSA continue to experience the high number of wildfires occurrence and size of areas burnt and this may be a result of sparse firebreaks unlike in SWRA where there are welldeveloped firebreaks.

\section{Implications to research and research practice}

The conservation implication of our finding is that robust fire management plans need to take into account an ecosystem approach that includes communities adjacent to protected areas. The occurrence of wildfires is influenced by numerous factors. Research in the future should explore in detail how different determinants and driving factors work together to influence wildfires.

\section{CONCLUSION AND RECOMMENDATIONS}

This paper investigated the influences of annual rainfall on spatial fire occurrence across the landscape of CNP, CSA, and SWRI, in the northwest, Zimbabwe. We observed and highlighted that total annual rainfall alone does not necessarily determine wildfire occurrence. Other factors including anthropogenic activities in the adjacent communities and natural factors apart from annual precipitation may be drivers of wildlife occurrence. The overall reduction in fire incidences in recent years highlights that proper fire management plans, when implemented in 
a spatially strategic manner, can help to decrease wildfire occurrence and improve protected area protection against wildfire. We advocate for an ecosystem approach to research and fire management that includes adjacent communities to reduce wildfires in protected areas.

\section{Future Research}

Future research is required on community perception on the causes of wildfires in protected area-community settlements to fully understand the dynamics of wildfires in the semi-arid savanna region. The occurrence of wildfires in the context of climate change main variables such as temperature and precipitation need to be further explored.

\section{Author Contribution}

Innocent Mahakata: Conceptualisation, Methodology, Data collection and analysis, and Writing, Mukululi Ndlovu: Conceptualisation, Methodology, and Writing.

\section{Acknowledgment}

We are grateful to the Director-General of the Zimbabwe Parks and Wildlife Management Authority for permission to use the wildfires and rainfall data from CNP, CSA, and SWRA. Many former and present research officers in CNP, CSA, and SWRI have contributed to the collection and updating of rainfall and wildfires data over the years used in this study. We also acknowledge the inputs from anonymous reviewers which helped improve this manuscript.

\section{Declaration of interest}

The authors declare no conflict of interest.

\section{Project Funding}

No funding Grant was received for the project.

\section{REFERENCE}

Alaback, P., Veblen, T. T., Whitlock, C., Lara, A., Kitzberger, T., \& Villalba, R. (2003). Climatic and Human Influences on Fire Regimes in Temperate Forest Ecosystems in North and South America (Issue January). https://doi.org/10.1007/978-3-662-05238-9_5

Balfour, D. A., \& Howison, O. E. (2015). Spatial and temporal variation in a mesic savanna fire regime: Responses to variation in annual rainfall Spatial and temporal variation in a mesic savanna fire regime: responses. February. https://doi.org/10.2989/10220110209485773

Bistinas, I., Harrison, S. P., Prentice, I. C., \& Pereira, J. M. C. (2014). Causal relationships versus emergent patterns in the global controls of fire frequency. Biogeosciences, 11(18), 5087-5101. https://doi.org/10.5194/bg-11-5087-2014

Bowman, D. M. J. S., Balch, J., Artaxo, P., Bond, W. J., Cochrane, M. A., D’Antonio, C. M., Defries, R., Johnston, F. H., Keeley, J. E., Krawchuk, M. A., Kull, C. A., Mack, M., Moritz, M. A., Pyne, S., Roos, C. I., Scott, A. C., Sodhi, N. S., \& Swetnam, T. W. (2011). The human dimension of fire regimes on Earth. Journal of Biogeography, 38(12), 2223-2236. https://doi.org/10.1111/j.1365-2699.2011.02595.x 
Bradstock, R. A., Hammill, K. A., Collins, L., \& Price, O. (2010). Effects of weather, fuel, and terrain on fire severity in topographically diverse landscapes of south-eastern Australia. Landscape Ecology, 25(4), 607-619. https://doi.org/10.1007/s10980-0099443-8

Chingono, T. T., \& Mbohwa, C. (2015). Fire hazard modeling in southern Africa. Lecture Notes in Engineering and Computer Science, 2219, 514-519.

Csiszar, I., Denis, L., Giglio, L., Justice, C. O., \& Hewson, J. (2005). Global fire activity from two years of MODIS data. International Journal of Wildland Fire, 14(2), 117130. https://doi.org/10.1071/WF03078

Cumming, D. H. M. (2008). Large-scale conservation planning and priorities for the Kavango-Zambezi Transfrontier Conservation Area. August, 124.

De Vasconcelos, M. J. P., Silva, S., Tomé, M., Alvim, M., \& Pereira, J. M. C. (2001). Spatial prediction of fire ignition probabilities: Comparing logistic regression and neural networks. Photogrammetric Engineering and Remote Sensing, 67(1), 73-81.

Dudley, J. P., Criag, G. C., Gibson, D. S. C., Haynes, G., \& Klimowicz, J. (2001). Drought mortality of bush elephants in Hwange National Park, Zimbabwe. African Journal of Ecology, 39(2), 187-194. https://doi.org/10.1046/j.0141-6707.2000.00297.x

Falk, D. A., Heyerdahl, E. K., Brown, P. M., Farris, C., Fulé, P. Z., McKenzie, D., Swetnam, T. W., Taylor, A. H., \& Van Horne, M. L. (2011). Multi-scale controls of historical forest-fire regimes: New insights from fire-scar networks. Frontiers in Ecology and the Environment, 9(8), 446-454. https://doi.org/10.1890/100052

Krawchuk, M. A., Moritz, M. A., Parisien, M. A., Van Dorn, J., \& Hayhoe, K. (2009). Global phylogeography: The current and future distribution of wildfire. PLOS ONE, 4(4). https://doi.org/10.1371/journal.pone.0005102

Lafon, C. W., \& Quiring, S. M. (2012). Relationships of fire and precipitation regimes in temperate forests of the eastern United States. Earth Interactions, 16(11). https://doi.org/10.1175/2012EI000442.1

Mapaure, I. N., \& Campbell, B. M. (2002). Changes in miombo woodland cover - elephants and fire. African Journal of Ecology, 40(3), 212-219.

Mapaure, I., Campbell, B. M., \& Gambiza, J. (2009). Evaluation of the effectiveness of an early peripheral burning strategy in controlling wildfires in north-western Zimbabwe. African Journal of Ecology, 47(4), 518-527. https://doi.org/10.1111/j.13652028.2008.00976.x

Mpakairi, K. S., Tagwireyi, P., Ndaimani, H., \& Madiri, H. T. (2018). Distribution of wildland fires and possible hotspots for the Zimbabwean component of KavangoZambezi Transfrontier Conservation Area Distribution of wildland fires and possible hotspots for the Zimbabwean component of Kavango-Zambezi Transfrontier Conserv. South African Geographical Journal, 00(00), 1-11. https://doi.org/10.1080/03736245.2018.1541023

Nelson, A., \& Chomitz, K. M. (2011). Effectiveness of strict vs. multiple-use protected areas in reducing tropical forest fires: A global analysis using matching methods. PLoS ONE, 6(8). https://doi.org/10.1371/journal.pone.0022722

Nyamadzawo, G., Gwenzi, W., Kanda, A., Kundhlande, A., \& Masona, C. (2013). Understanding the causes, socio-economic and environmental impacts, and management of veld fires in tropical Zimbabwe. 2(1), 1. https://doi.org/10.1186/21930414-2-2

Renard, Q., Ṕlissier, R., Ramesh, B. R., \& Kodandapani, N. (2012). Environmental susceptibility model for predicting forest fire occurrence in the Western Ghats of India. 
International Journal of Wildland Fire, 21(4), 368-379. https://doi.org/10.1071/WF10109

Smit, I. P. J., Smit, C. F., Govender, N., Linde, M. Van Der, \& Macfadyen, S. (2013). Rainfall, geology, and landscape position generate large-scale spatiotemporal fire pattern heterogeneity in an African savanna. May 2012, 447-459. https://doi.org/10.1111/j.1600-0587.2012.07555.x

Srivastava, S. K., Saran, S., de By, R. A., \& Dadhwal, V. K. (2014). A geo-information system approach for forest fire likelihood based on causative and anti-causative factors. International Journal of Geographical Information Science, 28(3), 427-454. https://doi.org/10.1080/13658816.2013.797984

Westerling, A. L., Hidalgo, H. G., Cayan, D. R., \& Swetnam, T. W. (2006). Warming and earlier spring increase western U.S. forest wildfire activity. Science, 313(5789), 940943. https://doi.org/10.1126/science.1128834

Wilgen, B W V A N, \& Govender, N. (2004). Response of Savanna Fire Regimes to Changing Fire-Management Policies in a Large African. 18(6), 1533-1540.

Wilgen, Brian W V A N. (2006). The effect of fire season, fire frequency, rainfall and. 748758. https://doi.org/10.1111/j.1365-2664.2006.01184.x

Zar, J. H. (1999). Biostatistical analysis. Pearson Education India.

Zedler, P. H., and Seiger, L. A. (2000). Age mosaics and fire size in chaparral: a simulation study. 2nd interface between ecology and land development in California. 